\title{
Efficacy of Intraoperative Administration of Topical Tranexamic Acid Solution on Blood Loss During Surgical Removal of Impacted Mandibular Third Molar
}

\author{
Subhashini Ramasubbuํㅜ, Shivangi Gaur², Abdul Wahab PU³, Madhulaxmi Marimuthu ${ }^{4}$ \\ 1,2,3,4 Department of Oral and Maxillofacial Surgery, Saveetha Dental College and Hospitals, SIMATS, \\ Velappanchavadi, Chennai, Tamil Nadu, India.
}

\section{ABSTRACT}

\section{BACKGROUND}

Perioperative haemorrhage is an important concern during any surgical procedure. The purpose of this study was to assess the effect of tranexamic acid (TXA) irrigation on perioperative haemorrhage during the surgical removal of impacted mandibular third molar.

\section{METHODS}

In this double-blind, randomized controlled clinical trial, 120 participants who underwent surgical removal of horizontally impacted mandibular third molar were divided into 2 groups. The patients in the Group 1 received $0.9 \%$ normal saline for irrigation during the procedure and the patients in the Group 2 received TXA irrigation with normal saline $(1 \mathrm{mg} / \mathrm{mL})$, age, gender, operation duration, amount of blood loss and visual assessment of surgical field were the variables that were studied. The use of TXA solution for irrigation was the predictive factor of the study.

\section{RESULTS}

Each group consisted of 60 patients. Group 1 consisted of 31 male patients (51.7\%) and 29 female patients (48.3\%) and group 2 consisted of 30 male patients (50\%) and 30 female patients $(50 \%)$. There was no difference in the distribution of the variables between the 2 groups, except for the duration of the operation. The mean operative time was $20.94 \pm 0.61$ minutes in group 1 and $26.17 \pm 0.98$ minutes in group $2(\mathrm{P}>.05)$ which was not statistically significant. The mean intraoperative blood loss was $44.47 \pm 6.416 \mathrm{~mL}$ in group 1 and $84.73 \pm 7.861$ in group $2(\mathrm{P}<.05)$. The mean volume of irrigation was $100.08 \pm 7.658 \mathrm{~mL}$ in group 1 and $140.33 \pm 12.332 \mathrm{~mL}$ in group $2(\mathrm{P}<.05)$.

\section{CONCLUSIONS}

TXA is effective in reducing the risk of intraoperative blood loss in patients for whom substantial blood loss is anticipated.

\section{KEY WORDS}

Tranexamic Acid, TXA, Blood Loss, Third Molar Surgery, Impacted Tooth Removal.
Corresponding Author: Dr. Subhashini Ramasubbu, 218A, Alagai Nagar

Rajapalayam - 626117, Tamil Nadu, India.

E-mail: meetsubha07@gmail.com

DOI: $10.14260 /$ jemds $/ 2021 / 611$

How to Cite This Article:

Ramasubbu S, Gaur S, Wahab APU, et al. Efficacy of intraoperative administration of topical tranexamic acid solution on blood loss during surgical removal of impacted mandibular third molar. J Evolution Med Dent Sci 2021;10(35):2989-2993, DOI: 10.14260/jemds/2021/611

Submission 23-04-2021, Peer Review 29-06-2021, Acceptance 05-07-2021, Published 30-08-2021.

Copyright (C) 2021 Subhashini Ramasubbu et al. This is an open access article distributed under Creative Commons Attribution License [Attribution 4.0 International (CC BY 4.0)] 


\section{BACKGROUND}

Impacted third molar removal is the most common surgical procedure carried out in oral and maxillofacial surgery clinics and this procedure requires accurate planning and surgical skills. ${ }^{1}$ The patients who have infection, pericoronitis, pericoronal abscess, odontogenic pathologies like cysts and tumours associated with it, and who needs orthodontic corrections will undergo this surgical procedure. ${ }^{2}$

Blood is an important body fluid which provides nutrients to the cells. It has limited shelf life. Preservation of blood is costly and the processing is also complex. But the transfusion has its own complications which includes infections, blood borne diseases, and some acute complications like transfusion related acute lung injury and associated circulatory overload. Therefore, to overcome these issues preservation of blood is considered safe in all surgical procedures. ${ }^{3}$

To reduce intraoperative blood loss, some pharmacologic agents have been developed. Various studies have been done by authors to report the efficacy of these pharmacologic agents. In their studies they have reported that aprotinin, hemocoagulase and tranexamic acid (TXA) which are antifibrinolytics are successful in lowering blood transfusion. ${ }^{3,4}$ Tranexamic acid is an analog of lysine which is an amino acid. Tranexamic acid reduces blood loss by acting on plasminogen and hence the antifibrinolytic effect. It is effective in minimizing intra operative blood loss in various surgical procedures. There are no side effects for this drug as well as according to the previous literatures. ${ }^{5}$ Some studies stated that tranexamic acid formulations are successful in lowering blood loss. In maxillary sinus endoscopic surgery, topical TXA has been reported to decrease intraoperative blood loss $^{6}$ Some studies have evaluated the effect of intravenous as well as topical TXA on decreasing the intraoperative blood loss during orthognathic surgeries. ${ }^{6,7}$

TXA when administered intravenously before surgery decreased perioperative blood loss compared with placebo during the bimax jaw surgery, a type of orthognathic surgery. ${ }^{8}$ TXA administration intraoperatively is also efficacious by lowering the rate and volume of packed cell transfusion ${ }^{8,9}$ and thereby reducing the duration of admission in the hospital.. However, the use of TXA as a topical agent has no clear evidence on bleeding during surgery.

The purpose of the study was to assess the effect of topical TXA solution (1 mg / $\mathrm{mL}$ in $0.9 \%$ normal saline) intraoperatively on blood loss during the surgical removal of impacted mandibular third molar.

\section{METHODS}

A randomised, prospective controlled trial was done with a total of 120 patients, scheduled to undergo surgical removal of impacted mandibular third molar between August 2019 and January 2020, were enrolled to participate in this study in Saveetha dental college. All surgeons and patients were blinded to the randomization. 120 patients were randomly assigned to 1 of the 2 treatment groups. Simple randomisation was followed and the patients were selected using the SNOSE method.

The surgical procedures were carried out by post graduates of the same cadre in the Department of OMFS. Participants in group 1 (the control group) received $0.9 \%$ normal saline for irrigation and cooling of the instruments. In group 2 (the study group), participants received a TXA solution, $1 \mathrm{mg} / 1 \mathrm{ml}$ of $0.9 \%$ normal saline. The irrigation fluid was provided by a nurse just before the operation and used as needed throughout the procedure and the amounts used were recorded. Ethical clearance from the SRB committee was obtained before conducting the study (SDC / SIHEC / 2020 / DIASDATA / 0619 - 0320).

The inclusion criteria included 20- to 45-year-old otherwise healthy patients who were scheduled to undergo surgical removal of horizontally impacted mandibular third molar. Exclusion criteria included immunocompromised patients, patients undergoing anticoagulant therapy and patients with bleeding disorders.

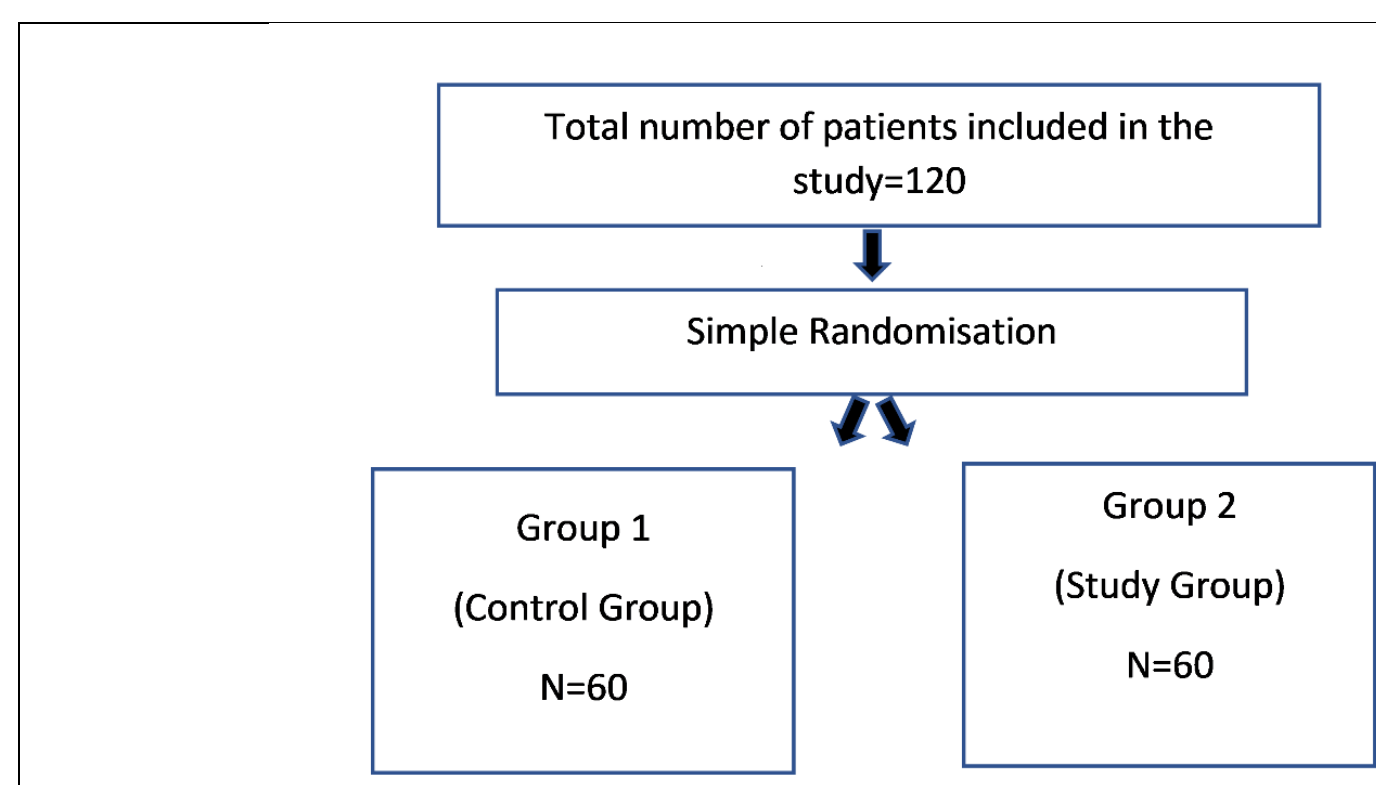


Blood loss was measured according to the amount of blood $(\mathrm{mL})$ accumulated in the suction container at the end of the case, after subtracting the amount of irrigation fluid that was used intraoperatively. In addition, all pieces of $44-\mathrm{cm}$ gauze were weighed at the end of the case, and each $1 \mathrm{~g}$ increase in the weight of the gauze was considered $1 \mathrm{~mL}$ of blood loss. Total operative duration was recorded for each patient.

Blood loss was considered as the primary outcome of the study. Age, gender, surgical time, the amount of irrigation solution used, visual assessment of surgical field, were the other variables that were analysed. The use of topical TXA solution was the predictive factor of the study.

\section{Statistical Analysis}

They were performed using SPSS for Windows, version 20 (IBM Corp, Armonk, NY). Changes in parametric variables were analysed using the unpaired Student $t$ test. Values of $\mathrm{P}$ $<.05$ were considered statistically significant.

\section{RESULTS}

The study comprised of 60 patients whose mean age of Range 20 - 45 years. 31 male patients $(51.7 \%)$ and 29 female patients (48.3\%), were allocated in Group 1 and 30 male patients (50\%) and 30 female patients (50\%) were allocated in Group 2. There was no difference in gender distribution among the groups. The mean age was $29.15 \pm 4.602$ years in group 1 and $28.48 \pm 4.862$ years in group 2 (Table 1$)$

\begin{tabular}{|c|c|c|c|c|}
\hline & $\mathbf{N}$ & Mean & Std Deviation & P - Value \\
\hline TXA Group & 60 & 29.15 & 4.602 & \multirow{2}{*}{0.12} \\
\hline Control Gp & 60 & 28.48 & 4.862 & \\
\hline \multicolumn{5}{|c|}{ Table 1. Mean Age of the Patients } \\
\hline
\end{tabular}

\begin{tabular}{|ccccc|}
\hline & N & Mean & Std Deviation P - Value \\
\hline TXA Group & 60 & 22.83 & 4.047 & \multirow{2}{*}{0.67} \\
Control Gp & 60 & 26.43 & 9.698 & \\
\hline \multicolumn{5}{c}{ Table 2. Duration } \\
\hline
\end{tabular}

\begin{tabular}{|ccccc|}
\hline N & Mean & Std Deviation P - Value \\
TXA & 60 & 43.72 & .660 & 0.01 \\
\hline Control Gp & 60 & 105.7 & 1.109 & \\
\hline \multicolumn{5}{c}{ Table 3. Mean Blood Loss } \\
\hline
\end{tabular}

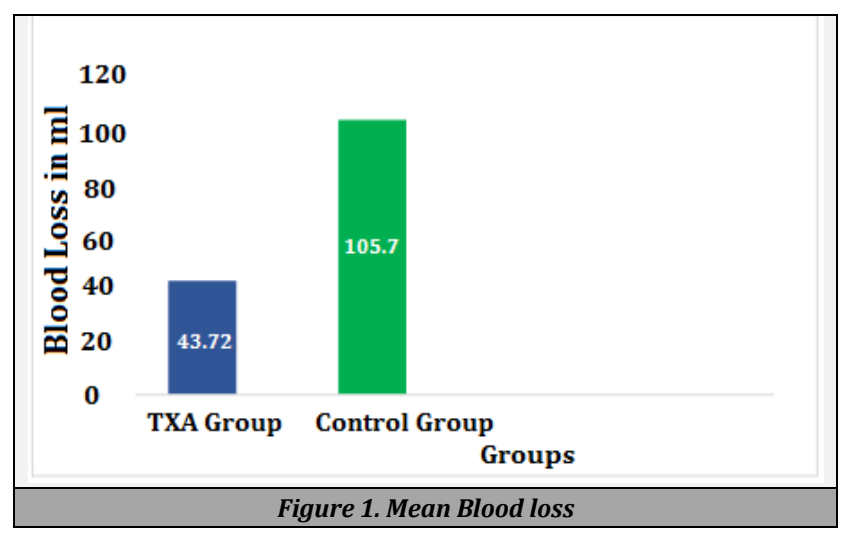

The mean operative time (Table 2) was $26.43 \pm 9.698$ minutes in group 1 and $22.83 \pm 4.047$ minutes in group 2 (P > .05). The mean intraoperative blood loss (Figure 1) was $105.73 \pm 7.861 \mathrm{~mL}$ in group 1 and $43.72 \pm 6.416 \mathrm{~mL}$ in group
$2(\mathrm{P}<.05)$. The mean volume of irrigation was $140.33 \pm 12.332$ $\mathrm{mL}$ in group 1 and $80.08 \pm 7.658 \mathrm{~mL}$ in group $2(\mathrm{P}<.05)$. The mean operative field score (Table 3 ) was $3.70 \pm 1.109$ in group 1 and $1.08 \pm 0.66$ in group 2 .

Figure 1 shows mean blood loss in tranexamic acid group and control group where $\mathrm{X}$ - axis denotes groups and $\mathrm{Y}$ - axis denotes blood loss in ml. Mean blood loss in the TXA group was $43.72 \mathrm{ml}$ and in the control group was $105.7 \mathrm{ml} . \mathrm{P}<0.05$ and it was statistically significant. This implies that there was a reduction of blood loss in the TXA group compared to control group.

Only one patient in the control group (Group 2) had infection following surgery. Thromboembolic events were not reported in any of the patients.

Based on our results, irrigation with TXA solution was associated with a statistically significant reduction in blood loss especially for inexperienced surgeons who could anticipate blood loss with a good quality of the surgical field, in spite of prolonged surgical time.

\section{DISCUSSION}

Impacted tooth is a tooth whose eruption is prevented by some barrier so that the tooth cannot erupt into the oral cavity. It is associated with acute complications like pain, infection, pericoronitis, and chronic complications like cysts and tumors, root resorption, bone loss. It is advised to remove surgically to avoid these complications. ${ }^{10}$

Most common intra operative complication of any surgical procedure is blood loss and hence it results in increased duration of the procedure. The possible postoperative consequences following surgery may be pain, swelling, trismus and inability to eat properly. ${ }^{11}$

In impacted third molar removal, there won't be severe bleeding. But in some situation, it is tough to handle bleeding. ${ }^{12}$ The patients may be healthy and in the same age group. The surgical procedures performed were even same. In Spite of this, there may be a challenge in controlling bleeding. ${ }^{13}$

The greater the blood loss, more the complications are. Blood loss can be balanced by transfusion of whole blood or packed cells depending on the situation but it has its own risk. The complications are infection, antigen - antibody reactions, hypothermia ${ }^{14,15}$ and cost. Various pharmacological agents like Aprotinin ${ }^{16}$ Hemocoagulase. ${ }^{17}$ Tranexamic acid 7 are used to control bleeding.

TXA (both intravenous and topical application) when it is administered intraoperatively, there is a significant decrease in blood loss and thereby reducing postoperative blood transfusion $19,6,8,20,21$ reported the single use of intravenous TXA in orthognathic surgery and they found that there was significant reduction in blood loss in the TXA group compared to the control group.22 It was found that TXA irrigation significantly reduced blood loss in bimaxillary osteotomy procedures. This is in accordance with our study. In our study we found that mean blood loss in TXA group was $44.47 \pm 6.416 \mathrm{~mL}$ and in control group was $84.73 \pm 7.861 \mathrm{~mL}$ $(\mathrm{P}<0.05)$ and it was statistically significant. ${ }^{23}$ It was found that a single bolus of TXA $10 \mathrm{cmg} / \mathrm{kg}$ improved the surgical field and surgeons' satisfaction compared to the placebo group. In our study, we found that TXA group had improved surgical 
field of $1.08 \pm 0.66$ ( 6 - point scale by Fromme et al. and Boezaart et al.) compared to control group $3.70 \pm 1.109$ (P< 0.05 ) and it was statistically significant.

The mean duration of the procedure was $26.17 \pm 0.98$ minutes in group 1 and $20.94 \pm 0.61$ minutes in group $2(\mathrm{P}>$ .05 ) and it was not statistically significant. But in a study by Vahedi R. et al. ${ }^{22}$ they found that there was a significant reduction in duration of the surgery.

\section{CONCLUSIONS}

In our study all the procedures were done by postgraduates of the same cadre. Inexperienced surgeons may anticipate blood loss and therefore there is a loss in the surgical field which increases the duration of the surgery. Therefore, we conclude that TXA irrigation is effective in controlling bleeding and it improves surgical field, especially for the inexperienced surgeons.

Data sharing statement provided by the authors is available with the full text of this article at jemds.com.

Financial or other competing interests: None.

Disclosure forms provided by the authors are available with the full text of this article at jemds.com.

\section{REFERENCES}

[1] Jaafer SS, Aldaghir OM, Hanfoosh HS, et al. Incidence of periodontal pocket development in distal root of mandibular second molar following impacted third molar removal in compare to using bone graft \& platelet rich plasma. International Journal of Psychosocial Rehabilitation 2020;24(5):219-24.

[2] Sahu S, Patley A, Kharsan V, et al. Comparative evaluation of efficacy and latency of twin mix vs $2 \%$ lignocaine HCL with 1:80000 epinephrine in surgical removal of impacted mandibular third molar. J Family Med Prim Care 2020;9(2):904-8.

[3] Brecher ME. Calculation of blood loss. Chap - 25. In: Maniatis A, van der Linden P, Hardy JF, eds. Alternatives to Blood Transfusion in Transfusion Medicine $2^{\text {nd }}$ edn. John Wiley and Sons, Inc., 2010: p. 303-12.

[4] Belay ES, O’Donnell J, Flamant E, et al. Intravenous tranexamic acid versus topical thrombin in shoulder arthroplasty: a comparative study. J Shoulder Elbow Surg 2021;30(2):312-16.

[5] Fischer k, Awudi E, Varon J, et al. Role of tranexamic acid in the clinical setting. Cureus 2020;12(5):e8221.

[6] Kim DH, Kim S, Kang H, et al. Efficacy of tranexamic acid on operative bleeding in endoscopic sinus surgery: a meta-analysis and systematic review. Laryngoscope 2019;129(4):800-7.

[7] Tabrizi R. Should we use prophylactic tranexamic acid in orthognathic surgery to decrease blood loss? Int J Oral Maxillofac Surg 2018;47(11):1504.

[8] Apipan B, Rummasak D, Narainthonsaenee T. The effect of different dosage regimens of tranexamic acid on blood loss in bimaxillary osteotomy: a randomized, doubleblind, placebo - controlled study. Int J Oral Maxillofac Surg
2018;47(11):1504-5.

[9] Yuan ZF, Yin H, Ma WP, et al. The combined effect of administration of intravenous and topical tranexamic acid on blood loss and transfusion rate in total knee arthroplasty. Bone \& Joint Research 2016;5(8):353-61.

[10] Candotto V, Oberti L, Gabrione F, et al. Complication in third molar extractions. J Biol Regul Homeost Agents 2019;33(3 Suppl 1):169-72.

[11] Aksoy MÇ, Tuzum MS, Baykul T. Relationships between surgical difficulty and postoperative complications in mandibular third molar surgery. Annals of International Medical and Dental Research 2018;4:11-17.

[12] Senghore N, Harris M. The effect of tranexamic acid (cyclokapron) on blood loss after third molar extraction under a day case general anaesthetic. British Dental Journal 1999;186(12):634-6.

[13] Yamada SI, Hasegawa T, Soutome S, et al. Prevalence of and risk factors for postoperative hemorrhage after lower third molar extraction on warfarin therapy: a multicenter retrospective study in Japan. Odontology 2020;108(3):462-9.

[14] Boissonneault A, Schenker ML, Maceroli M, et al. Impact of intraoperative hypothermia on blood loss and transfusion requirements in patients with pelvic and Acetabular Trauma. Orthopaedic Trauma Association 2019. http://dx.doi.org/10.26226/morressier. 5cffabaef6074e97f94aae5c

[15] Song C, Liu C, Wei R, et al. Predictors associated with perioperative blood transfusion and intraoperative blood loss in thoracolumbar tuberculosis. January 2020. http://dx.doi.org/10.21203/rs.2.21729/v1

[16] Neligan PC, Plastic Surgery Educational Foundation DATA Committee. Aprotinin: role in minimizing perioperative blood loss. Plastic and Reconstructive Surgery 2005;116(1):324-7.

[17] Lu S, Han M, Song Y, et al. Hemocoagulase agkistrodon can prevent bleeding and induce hypofibrinogenemia in hepatic disease cases. Int J Clin Pharmacol Ther 2020;58(6):351-3.

[18] Roberts I, Prieto-Merino D, Manno D. Mechanism of action of tranexamic acid in bleeding trauma patients: an exploratory analysis of data from the CRASH - 2 trial. Critical Care 2014;18(7):685.

[19] Kirksey MA, Wilson LA, Fiasconaro M, et al. Tranexamic acid administration during total joint arthroplasty surgery is not associated with an increased risk of perioperative seizures: a national database analysis. Reg Anesth Pain Med 2020;45(7):505-8.

[20] Choi WS, Irwin MG, Samman N. The effect of tranexamic acid on blood loss during orthognathic surgery: a randomized controlled trial. J Oral Maxillofac Surg 2009;67(1):125-33.

[21] Sun L, Guo R, Feng Y. Efficacy and safety of tranexamic acid in bimaxillary orthognathic surgery. Plastic Surgery 2020;28(2):94-104.

[22] Eftekharian H, Vahedi R, Karagah T, et al. Effect of tranexamic acid irrigation on perioperative blood loss during orthognathic surgery: a double-blind, randomized controlled clinical trial. J Oral Maxillofac Surg 2015;73(1):129-33.

[23] Durga P, Raavula P, Gurajala I, et al. Evaluation of the efficacy of tranexamic acid on the surgical field in primary 
cleft palate surgery on children - a prospective, randomized clinical study. Cleft Palate Craniofac J

2015;52(5):e183-7. 